\title{
Quantifying Solvent Effects on Polymer Surface Grafting
}

Lukas Michalek, ${ }^{\dagger, \ddagger}$ Kai Mundsinger, ${ }^{,+\ddagger}$ Leonie Barner ${ }^{\dagger,+, *}$ and Christopher Barner-Kowollik ${ }^{+, \S, *}$

†School of Chemistry, Physics and Mechanical Engineering, Institute for Future Environments, Queensland University of Technology (QUT), 2 George Street, QLD 4000, Brisbane, Australia. E mail:

leonie.barner@qut.edu.au, christopher.barnerkowollik@qut.edu.au; http://www.macroarc.org

+Institut für Biologische Grenzflächen (IBG), Karlsruhe Institute of Technology (KIT), Hermann-von-Helmholtz-Platz 1, 76344 Eggenstein-Leopoldshafen, Germany

\$Macromolecular Architectures, Institut für Technische Chemie und Polymerchemie (ITCP), Karlsruhe Institute of Technology (KIT), Engesserstrasse 18, 76128 Karlsruhe, Germany. E-mail: christopher.barner-kowollik@kit.edu $\ddagger$ These authors contributed equally. 


\section{Table of Contents}

\section{Experimental Procedures}

\subsection{Materials and Methods}

1.1.1 Size exclusion chromatography (SEC)

1.1.2 Number based molar mass distributions $\left(M D_{n}\right)$

1.1.3 Dynamic light scattering (DLS)

1.1.4 Nuclear magnetic resonance (NMR) spectroscopy

1.1.5 Transmission electron microscopy (TEM)

1.1.6 Particle size analysis

Synthesis

1.2.1 Synthesis of 4-(3-(triethoxysilyl)propylcarbamoyl)-2-cyanobutan-2-yl benzodithioate CTA1

4

1.2.2 Synthesis of RAFT-PMMA P1

1.2.3 Synthesis of silica nanoparticles

1.2.4 Grafting-to of P1 on silica nanoparticles

\section{NMR Spectra}

2.1 Figure $\mathrm{S} 1{ }^{1} \mathrm{H}-\mathrm{NMR}\left(\mathrm{CDCl}_{3}\right)$ of CTA1

2.2 Figure $\mathbf{S} 2{ }^{1} \mathrm{H}-\mathrm{NMR}\left(\mathrm{CDCl}_{3}\right)$ of $\mathbf{P} 1$

3 Size Exclusion Chromatography

3.1 Figure S3 Mass (green) and number based (blue) MMD of P1. $M_{\mathrm{n}} 216100 \mathrm{~g} \cdot \mathrm{mol}^{-1}, M_{\mathrm{w}} 289000 \mathrm{~g} \cdot \mathrm{mol}^{-1}, \oplus=1.34$

3.2 Figure S4 Relative molar mass distributions of all samples illustrating a grafting percentage of $50.4 \pm 1.5 \%$

4 Preferential grafting factor $k$

7.1 Figure S5 Preferential grafting factor curves

5 Transmission electron microscopy

5.1 Figure S6 Transmission electron micrograph of NP1 8

6 Dynamic light scattering

6.1 Figure S7 Hydrodynamic radii of P1 in DMAc and ethyl acetate 9

\section{Calculations}

7.1 Radius of Gyration

7.2 MMD calculations

7.3 Normalization of $M M D$

8 References 


\section{Experimental Procedures}

\subsection{Materials and Methods}

4-Cyano-4-(phenylcarbonothioylthio)pentanoic acid (> 97\%, Sigma Aldrich), 1-ethyl-3-(3-dimethylaminopropyl)carbodiimide (EDC, $\geq 98 \%$, Sigma Aldrich), methanol ( $\geq 99.5 \%$, analytical reagent, Ajax Finechem), ethanol (analytical reagent, Ajax Finechem), acetone (analytical reagent, Ajax Finechem), ethyl acetate ( $\geq 99.8 \%$, Fisher Scientific), N,N-dimethylacetaminde (HPLC grade, Sigma Aldrich), tetraethyl orthosilicate (TEOS, $98 \%$ Sigma Aldrich), ammonia (28\%, Thermo Fisher), lithium bromide ( $\geq 99 \%$, Sigma Aldrich) and $n$ Pentane (analytical reagent, Ajax Finechem) were used as received. 2,2-Azobisisobutyronitrile (AIBN, 12 wt.-\% in acetone, Sigma Aldrich) was recrystallized twice from methanol prior to use. Methyl methacrylate (MMA, 99\%, $\leq 30$ ppm MEHQ as inhibitor, Sigma Aldrich) was passed over basic alumina. (3-amino-propyl)triethoxysilane ( $\geq 98 \%$, Sigma Aldrich) was distilled prior to use. Dichloromethane (DCM, HPLC grade, Ajax Finechem), toluene (HPLC grade, Fisher Chemicals) and THF (HPLC grade, Fisher Chemicals) were dried over columns filled with aluminium oxide and molecular sieves in a LC Technology Solutions Inc. SP1 solvent purification system.

\section{Size exclusion chromatography (SEC)}

The molar masses and molar mass distributions of the prepared polymers were determined on a PSS SECurity ${ }^{2}$ system consisting of a PSS SECurity Degasser, PSS SECurity TCC6000 Column Oven $\left(35^{\circ} \mathrm{C}\right)$, PSS SDV Column Set $(8 \times 150 \mathrm{~mm} 5 \mu \mathrm{m}$ Precolumn, $8 \times 300 \mathrm{~mm} 5 \mu \mathrm{m}$ Analytical Columns, $100000 \AA, 1000 \AA$ and $100 \AA$ ) and an Agilent 1260 Infinity Isocratic Pump, Agilent 1260 Infinity Standard Autosampler, Agilent 1260 Infinity Diode Array and Multiple Wavelength Detector (A: 254 nm, B: 360 nm), Agilent 1260 Infinity Refractive Index Detector $\left(35^{\circ} \mathrm{C}\right)$. HPLC grade THF, stabilized with BHT, was used as eluent at a flow rate of $1 \mathrm{~mL} \cdot \mathrm{min}^{-1}$. Narrow disperse linear poly(styrene) $\left(M_{\mathrm{n}}: 266 \mathrm{~g} \cdot \mathrm{mol}^{-1}\right.$ to $\left.2.52 \times 10^{6} \mathrm{~g} \cdot \mathrm{mol}^{-1}\right)$ and poly (methyl methacrylate) $\left(M_{\mathrm{n}}: 202 \mathrm{~g} \cdot \mathrm{mol}^{-1}\right.$ to $\left.2.2 \times 10^{6} \mathrm{~g} \cdot \mathrm{mol}^{-1}\right)$ standards (PSS ReadyCal) were used as calibrants. All samples were passed over $0.22 \mu \mathrm{m}$ PTFE membrane filters prior to analysis. Molar mass and dispersity analysis was performed in PSS WinGPC UniChrom software (version 8.2).

Every sample was measured three times and the resulting, virtually identical, traces were averaged. All traces were referenced to an internal standard to correct for eventual changes in elution behavior.

\section{Number based molar mass distributions $\left(M M D_{n}\right)$}

Depending on the employed detector, the $\mathrm{MMD}_{\mathrm{n}}$ can be obtained directly or via a simple calculation. A UV detector can be tuned to the absorption wavelength of the polymer end group, which results in a directly recorded $M_{M D_{n}}$. If, however, the end group is sensitive towards oxidation, like most RAFT derived end groups, this is unreliable. The refractive index signal instead is mass sensitive, implying it is proportional to the number of monomer units in the sample. Thus, RI detection returns the mass weighted concentration signal. If the ordinate values are divided by the respective molar mass of each slice concentration, a number (of polymer chains) weighted distribution is obtained.

\section{Dynamic Light Scattering (DLS)}

Polymer hydrodynamic radii were obtained via DLS using a Malvern Zetasizer NanoZS with $4 \mathrm{~mW}$ He-Ne laser at $633 \mathrm{~nm}$. Samples were filtered over $0.45 \mu \mathrm{m}$ membranes and measured at $25^{\circ} \mathrm{C}$ in quartz cuvettes. Data evaluation was performed in the Malvern Zetasizer software 7.11 .

\section{Nuclear magnetic resonance (NMR) spectroscopy}

${ }^{1} \mathrm{H}$ NMR-spectra were recorded on a Bruker 600 Ascend LH, equipped with a BBO-Probe $(5 \mathrm{~mm})$ with z-gradient $\left({ }^{1} \mathrm{H}\right.$ : $600 \mathrm{MHz}$,). The resonances are reported in chemical shift $\left(\delta=\mathrm{ppm}\right.$, rounded to two decimals) relative to the solvent signal of $\mathrm{CHCl}_{3}(7.26 \mathrm{ppm})$. Coupling constants $(J)$ are reported in Hz. Spectra were processed using Mestrelab Reasearch S.L. MestReNova 11.

\section{Transmission electron microscopy (TEM)}

Transmission electron micrographs were recorded on a JEOL TEM1400 transmission electron microscope. Samples were prepared on 200 mesh copper grids with a Formvar/Carbon support film by dip coating of the grid with reaction mixtures or sonicated dispersions. Images were acquired at $80 \mathrm{kV}$ in $4 \mathrm{k}$ by $4 \mathrm{k}$ using a TVIPS F416 CMOS camera.

\section{Particle size analysis}

TEM images were analyzed using $\mathrm{NIH}$ Image $\mathrm{2}^{[1]}$ in the $\mathrm{Fiji}^{[2]}$ distribution package. The image was divided in equal areas containing about 100 particles per area. All unconcealed particles per area were outlined using the elliptical selection tool. This way a minimum of 100 particles per image was analyzed. The area of the selected outline was then converted to the diameter $\left(D=2 \cdot \sqrt{\frac{A}{\pi}}\right)$ thereby approximating elliptical shapes as circular. The arithmetic mean diameter $(\bar{D}(1))$ as well as standard deviation $(\sigma(2))$ and standard error (SE (3)) were calculated in Microsoft Excel 2013.

$$
\begin{gathered}
\bar{D}=\frac{1}{n} \sum_{\mathrm{i}=1}^{n} D_{\mathrm{i}} \\
\sigma=\sqrt{\frac{1}{n}} \sum_{\mathrm{i}=1}^{n}\left(D_{\mathrm{i}}-D_{\text {mean }}\right)^{2} \\
S E=\frac{\sigma}{\sqrt{n}}
\end{gathered}
$$

$\bar{D}=$ arithmetic mean of the particle diameter

$n=$ number of particles evaluated

$D_{\mathrm{i}}=$ diameter of the particle $\mathrm{i}$.

$\sigma=$ standard deviation

$S E=$ standard error 


\subsection{Synthesis}

Synthesis of 4-(3-(triethoxysilyl)propylcarbamoyl)-2-cyanobutan-2-yl benzodithioate CTA1<smiles>CCO[Si](CCCNC(=O)CCC(C)(C#N)SC(=S)c1ccccc1)(OCC)OCC</smiles>

CTA1

The title compound was synthesized according to a literature procedure. ${ }^{[3]}$ 4-Cyano-4-(phenylcarbonothioylthio)pentanoic acid (757 mg $2.7 \mathrm{mmol}, 1.2$ eq.) and EDC (649 mg, $3.4 \mathrm{mmol}, 1.5 \mathrm{eq}$.) were dissolved in dry DCM (100 mL) under argon atmosphere using flame dried glassware. 3-Aminopropyltriethoxysilane $(529 \mu \mathrm{L}, 2.3 \mathrm{mmol}, 1 \mathrm{eq}$.) was added using a gas-tight syringe. The reaction was allowed to proceed for $3 \mathrm{~h}$ at ambient temperature. Subsequently, the reaction mixture was washed twice with saturated sodium hydrogen. The carbonate solution, twice with demineralized water, twice with brine and the organic phase was dried over magnesium sulfate. The solvent was removed under reduced pressure and the target compound 1 was obtained as red oil.

${ }^{1} \mathrm{H}-\mathrm{NMR}\left(600 \mathrm{MHz}\right.$, Chloroform- $\left.d, 25^{\circ} \mathrm{C}\right): \delta=7.90\left(\mathrm{~d},{ }^{3} \mathrm{~J}(\mathrm{H}, \mathrm{H})=7.3 \mathrm{~Hz}, 2 \mathrm{H}, \mathrm{CH}\right.$ arom. $), 7.56\left(\mathrm{t},{ }^{3} \mathrm{~J}(\mathrm{H}, \mathrm{H})=7.4 \mathrm{~Hz}, 1 \mathrm{H}, \mathrm{CH}\right.$ arom. $), 7.39$ (t, ${ }^{3} \mathrm{~J}(\mathrm{H}, \mathrm{H})=7.9 \mathrm{~Hz}, 2 \mathrm{H}, \mathrm{CH}$ arom.), $5.96(\mathrm{~s}, 1 \mathrm{H}, \mathrm{NH}), 3.82\left(\mathrm{q},{ }^{3} \mathrm{~J}(\mathrm{H}, \mathrm{H})=7.0 \mathrm{~Hz}, 6 \mathrm{H}, \mathrm{CH}_{2}\right), 3.27\left(\mathrm{q},{ }^{3} \mathrm{~J}(\mathrm{H}, \mathrm{H})=6.7 \mathrm{~Hz}, 2 \mathrm{H}, \mathrm{CH}_{2}\right), 2.65$ $-2.38\left(\mathrm{~m}, 4 \mathrm{H}, \mathrm{CH}_{2}\right), 1.93\left(\mathrm{~s}, 3 \mathrm{H}, \mathrm{CH}_{3}\right), 1.64$ (quin, $\left.{ }^{3} \mathrm{~J}(\mathrm{H}, \mathrm{H})=7.0 \mathrm{~Hz}, 2 \mathrm{H}, \mathrm{CH}_{2}\right), 1.23\left(\mathrm{t},{ }^{3} \mathrm{~J}(\mathrm{H}, \mathrm{H})=7.0 \mathrm{~Hz}, 9 \mathrm{H}, \mathrm{CH}_{3}\right), 0.64\left(\mathrm{t},{ }^{3} \mathrm{~J}(\mathrm{H}, \mathrm{H})=\right.$ $\left.8.0 \mathrm{~Hz}, 2 \mathrm{H}, \mathrm{CH}_{2}\right)$

\section{Synthesis of RAFT-PMMA P1-5}<smiles>CCO[Si](CCCNC(=O)CCC(C)(C#N)CC(C)(CSC(=S)c1ccccc1)C(=O)OC)(OCC)OCC</smiles>

The polymer samples were prepared according to literature known procedures. ${ }^{[4]}$ A stock solution of MMA (6.55 M) and AIBN (1.8 mM) in toluene was degassed by three freeze-pump-thaw cycles. The stock solution was then added to septum vials containing weighed amounts of RAFT chain transfer agent (RAFT CTA) 1 and purged with argon for $10 \mathrm{~min}$. The vials were subsequently heated to $80{ }^{\circ} \mathrm{C}$ in an aluminium heating block and the polymerization was allowed to proceed for $16 \mathrm{~h}$. The contents of each vial were dissolved in $4 \mathrm{~mL}$ THF and the polymers precipitated in methanol and subsequently in $n$-pentane. The polymers were dried in vacuo ( $\leq 0.002 \mathrm{mbar}$, $24 \mathrm{~h}$ ) and stored under argon and exclusion of light.

${ }^{1} \mathrm{H}-\mathrm{NMR}(\mathbf{P 1})\left(600 \mathrm{MHz}\right.$, Chloroform-d, $\left.25^{\circ} \mathrm{C}\right): \delta=7.90$ (m, $2 \mathrm{H}, \mathrm{CH}$ arom.), $7.56(\mathrm{~m}, 1 \mathrm{H}, \mathrm{CH}$ arom.), 7.39 (m, $2 \mathrm{H}, \mathrm{CH}$ arom.), 5.96 $(\mathrm{s}, 1 \mathrm{H}, \mathrm{NH}), 3.82\left(\mathrm{q},{ }^{3} \mathrm{~J}(\mathrm{H}, \mathrm{H})=7.0 \mathrm{~Hz}, 6 \mathrm{H}, \mathrm{CH}_{2}\right), 3.27\left(\mathrm{q},{ }^{3} \mathrm{~J}(\mathrm{H}, \mathrm{H})=6.7 \mathrm{~Hz}, 2 \mathrm{H}, \mathrm{CH}_{2}\right), 2.65-2.38\left(\mathrm{~m}, 4 \mathrm{H}, \mathrm{CH}_{2}\right), 1.93\left(\mathrm{~s}, 3 \mathrm{H}, \mathrm{CH}_{3}\right)$, 1.64 (quin, $\left.{ }^{3} \mathrm{~J}(\mathrm{H}, \mathrm{H})=7.0 \mathrm{~Hz}, 2 \mathrm{H}, \mathrm{CH}_{2}\right), 1.23\left(\mathrm{t},{ }^{3} \mathrm{~J}(\mathrm{H}, \mathrm{H})=7.0 \mathrm{~Hz}, 9 \mathrm{H}, \mathrm{CH}_{3}\right), 0.64\left(\mathrm{t},{ }^{3} \mathrm{~J}(\mathrm{H}, \mathrm{H})=8.0 \mathrm{~Hz}, 2 \mathrm{H}, \mathrm{CH}_{2}\right)$

Table S1 Molar mass and dispersity of PMMA via RAFT polymerization of MMA (6.55 M in toluene) with AIBN (1.8 mM) as initiator and 2 as RAFT CTA for $16 \mathrm{~h}$ at $80^{\circ} \mathrm{C}$

\begin{tabular}{|c|c|c|c|c|c|c|c|}
\hline Sample & $M_{\mathrm{n}, \text { theo. }}{ }^{[\mathrm{a}]}$ & MMA & AIBN & RAFT CTA & $M_{\mathrm{n}, \mathrm{GPC}}$ & $M_{\mathrm{w}, \mathrm{GPC}}$ & $\theta_{\mathrm{GPC}}$ \\
\hline & $\mathrm{g} \cdot \mathrm{mol}^{-1}$ & $\mathrm{M}$ & $\mathrm{mM}$ & $\mathrm{mM}$ & $\mathrm{g} \cdot \mathrm{mol}^{-1}$ & $\mathrm{~g} \cdot \mathrm{mol}^{-1}$ & \\
\hline P1 & 396,000 & 6.55 & 1.8 & 1.66 & 216,100 & 289,000 & 1.34 \\
\hline
\end{tabular}

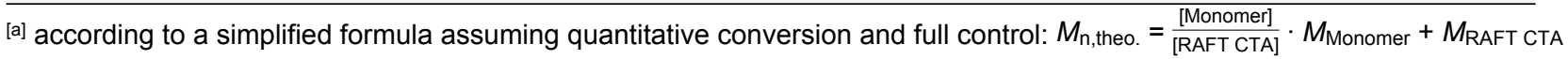

\section{Synthesis of silica nanoparticles}

Silica nanoparticles were synthesized according to a procedure adopted from Carcouët ${ }^{[5]}$. A mixture of TEOS (100 mL), 2-propanol $(75 \mathrm{~mL})$ and methanol $(25 \mathrm{~mL})$ was added via a dropping funnel within 60 min under stirring $(550 \mathrm{rpm}, 3 \mathrm{~cm}$ elliptical stir bar) to a solution of ammonia $\left(210 \mathrm{~mL}, 25 \%\right.$ in water) in isopropanol $(750 \mathrm{~mL})$ and methanol $(250 \mathrm{~mL})$ in a $3 \mathrm{~L}$ round bottom flask at $25{ }^{\circ} \mathrm{C}$. The mixture was stirred overnight and particles were collected by centrifugation for $20 \mathrm{~min}$ at $9000 \mathrm{rpm}$. The particles NP1 were washed twice with water and thrice with methanol via dispersion under sonication and subsequent centrifugation prior to drying in vacuo (<0.001 mbar) for $72 \mathrm{~h}$. 
Grafting-to of $\boldsymbol{P 1}$ on silica nanoparticles

Solutions of $4 \mathrm{mg} \cdot \mathrm{mL}^{-1}$ of P5 in six different solvents (THF S1, Toluene S2, Acetone S3, Ethyl acetate (EA) S4, DMAc containing 0.08 wt.-\% $\mathrm{LiBr} \mathbf{S 5}$ ) were prepared by dissolving $\mathbf{P 1}$ in the respective solvent overnight at $30^{\circ} \mathrm{C}$. Dispersions of silica nanoparticles containing $400 \mathrm{mg} \cdot \mathrm{mL}^{-1}$ nanoparticles were prepared by sonicating the appropriate amount of $\mathrm{SiO}_{2} \mathrm{NPs}$ in the respective solvent (S15) two times for $5 \mathrm{~min}$ each. Subsequently $2.5 \mathrm{~mL}$ polymer solution and $2.5 \mathrm{~mL}$ nanoparticle dispersion of each solvent were combined in an enclosed septum vial and heated to $50{ }^{\circ} \mathrm{C}$ for $7 \mathrm{~d}$ under stirring. The particles were separated via centrifugation and washed twice with THF and Toluene. The supernatants were combined and the solvent evaporated under reduced pressure. The residue was taken up in THF and submitted to SEC analysis. 


\section{NMR Spectra}

${ }^{1} \mathrm{H}-\mathrm{NMR}\left(\mathrm{CDCl}_{3}\right)$ Silane-RAFT-CTA 1<smiles>CCO[Si](CCCNC(=O)CCC(C)(C#N)SC(=S)c1ccccc1)(OCC)OCC</smiles>

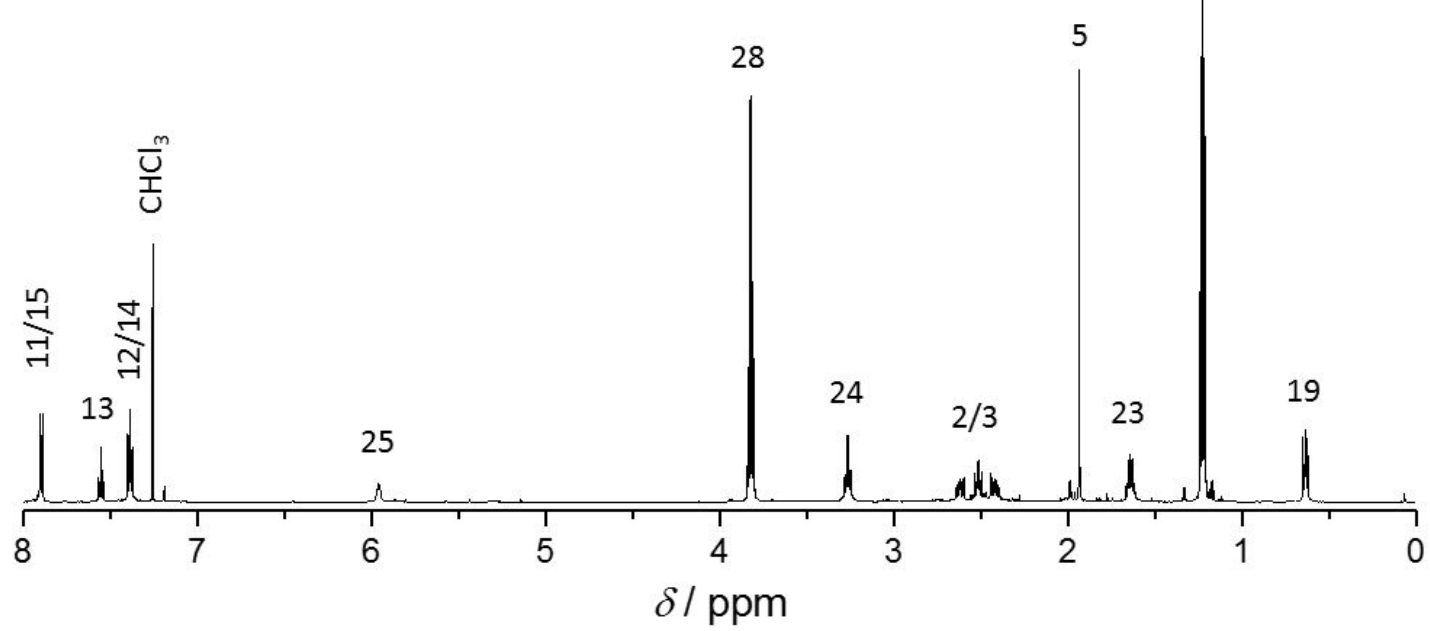

Figure $\mathrm{S} 1{ }^{1} \mathrm{H}-\mathrm{NMR}$ spectrum $\left(\mathrm{CDCl}_{3}\right)$ of CTA1.

${ }^{1} \mathrm{H}-\mathrm{NMR}\left(\mathrm{CDCl}_{3}\right)$ Silane-RAFT-PMMA P1<smiles>CCO[Si](CCCNC(=O)CCC(C)(C#N)CC(C)(C)C(=O)OC)(OCC)OCC</smiles>

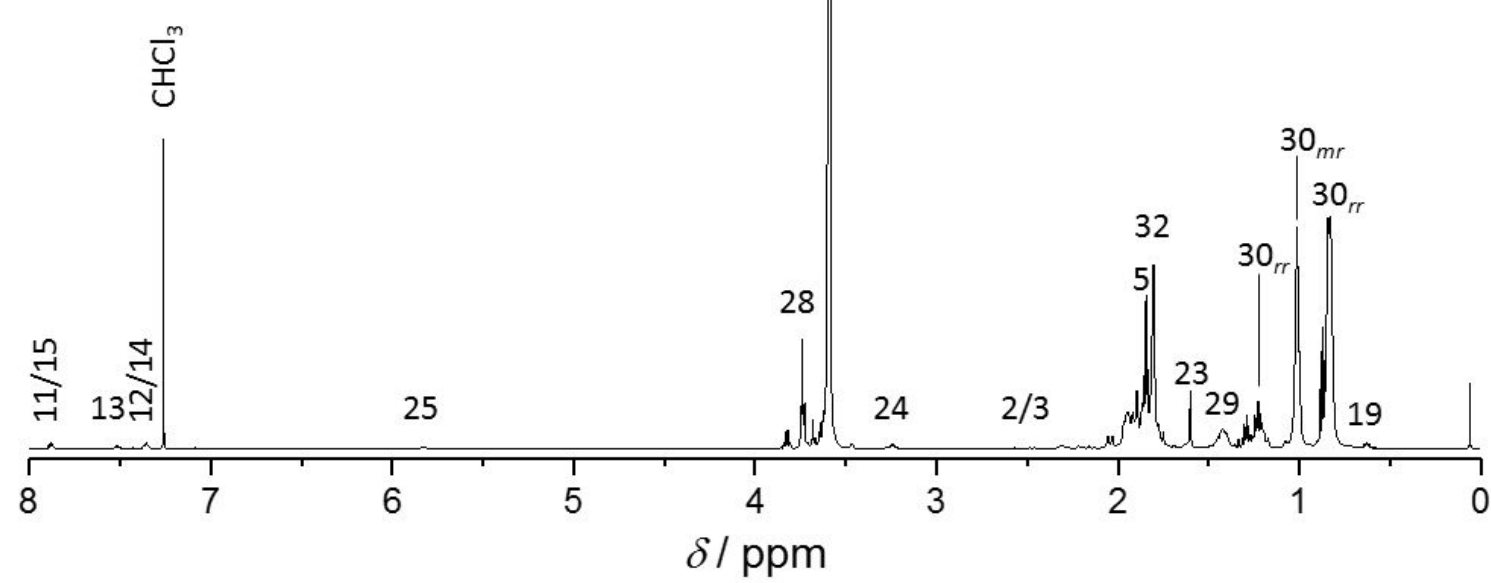

Figure S2 ${ }^{1} \mathrm{H}-\mathrm{NMR}$ spectrum $\left(\mathrm{CDCl}_{3}\right)$ of $\mathbf{P} 1$. 


\section{Size Exclusion Chromatography}

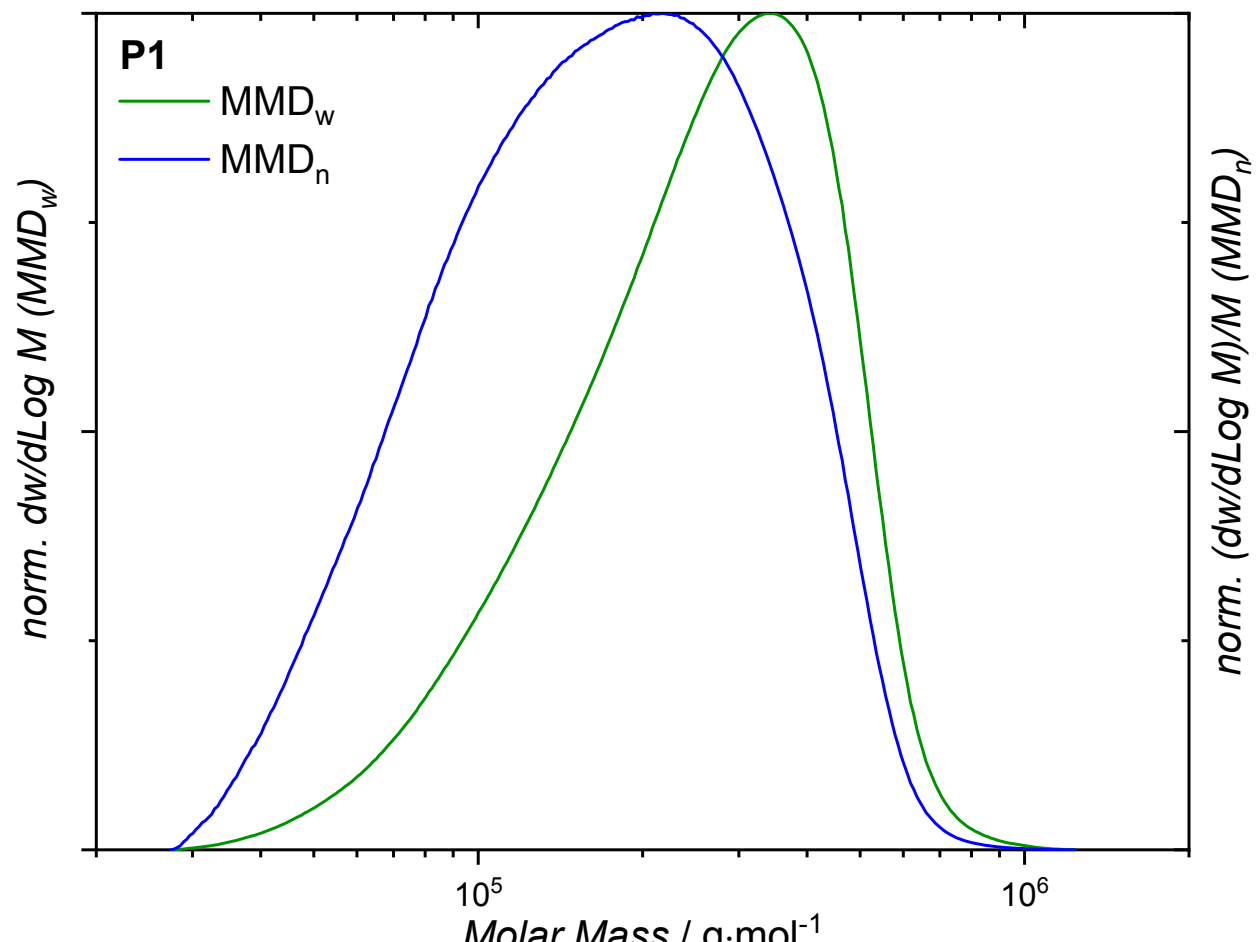

Figure S3 Mass (green) and number based (blue) MMD of P1. $M_{\mathrm{n}}=216,100 \mathrm{~g} \cdot \mathrm{mol}^{-1}, M_{\mathrm{w}}=289,000 \mathrm{~g} \cdot \mathrm{mol}{ }^{-1}, \Xi=1.34$.

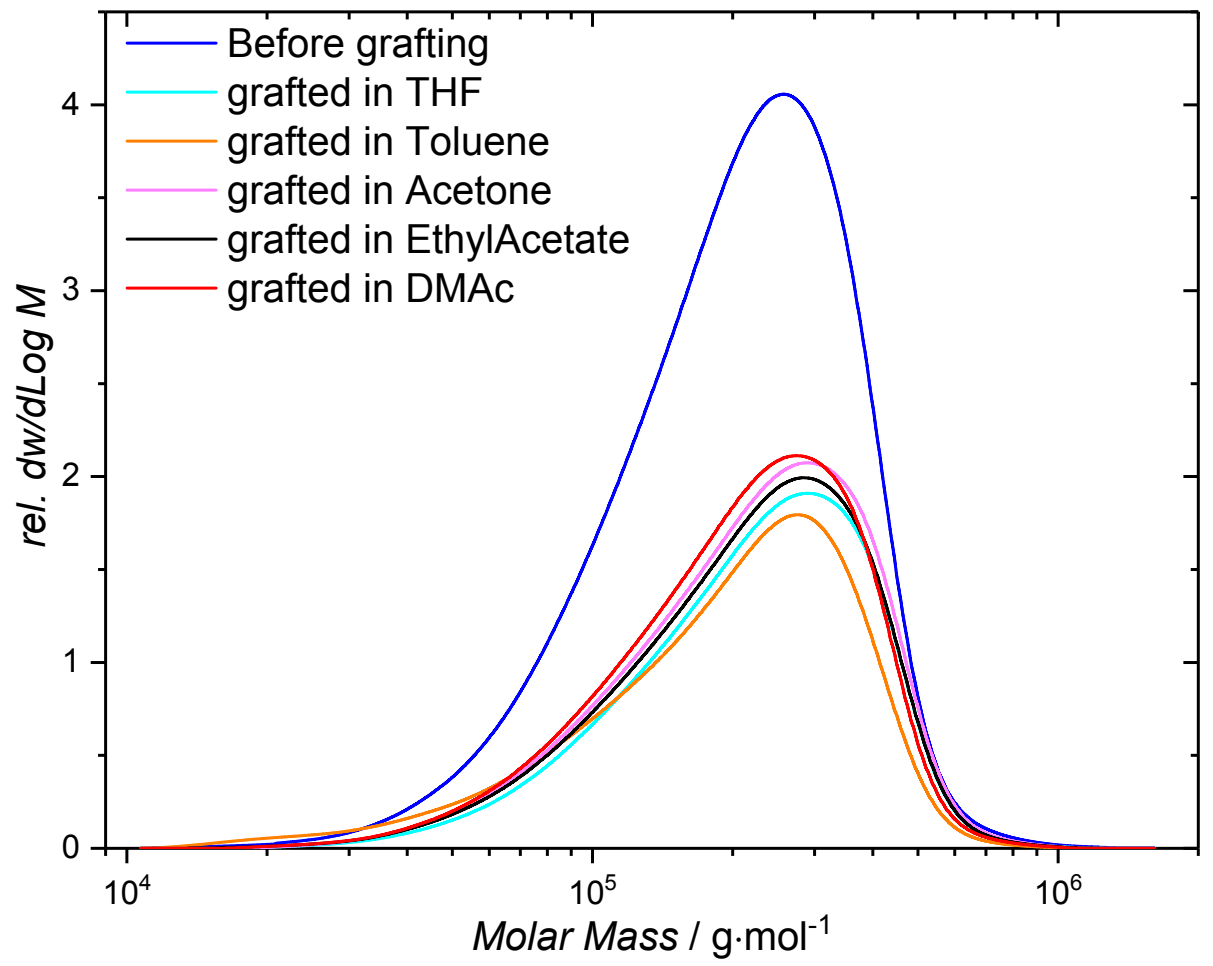

Figure S4 Relative molar mass distributions of all samples illustrating a grafting percentage of $50.4 \pm 1.5 \%$.

Table S2 Percentage of P5 grafted onto NP1.

\begin{tabular}{lc}
\hline Grafting solvent & Concentration change $/ \%$ \\
\hline THF & 52 \\
Toluene & 56 \\
Acetone & 47 \\
Ethyl acetate & 50 \\
DMAc/LiBr & 47 \\
\hline Average $=50.4 \pm 1.5 \% \sigma=3.4$ &
\end{tabular}

Average $=50.4 \pm 1.5 \% \sigma=3.4$ 


\section{Preferential grafting factor $k$}

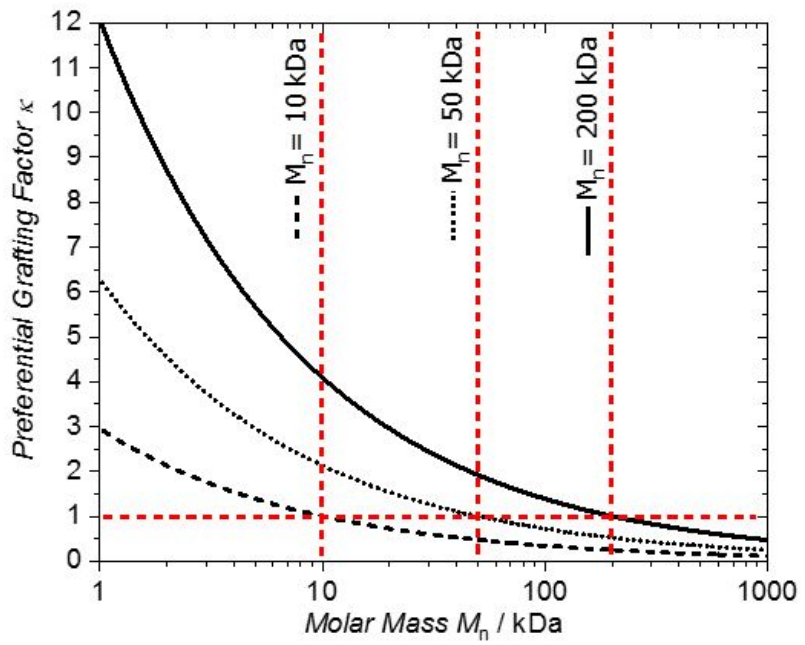

Figure S5 Preferential grafting factor $\kappa$ for three different number average molar masses $M_{\mathrm{n}}=10,50$ and $200 \mathrm{kDa}$ (dashed, dotted and solid line), calculated via Eq. (1). The intersection of the red dashed lines mark the points where $k=1$ for each sample, which is the number average molar mass of the sample. A larger value for $\mathrm{k}$ implies a stronger bias towards grafting of the particular molar mass.

\section{Transmission electron microscopy}

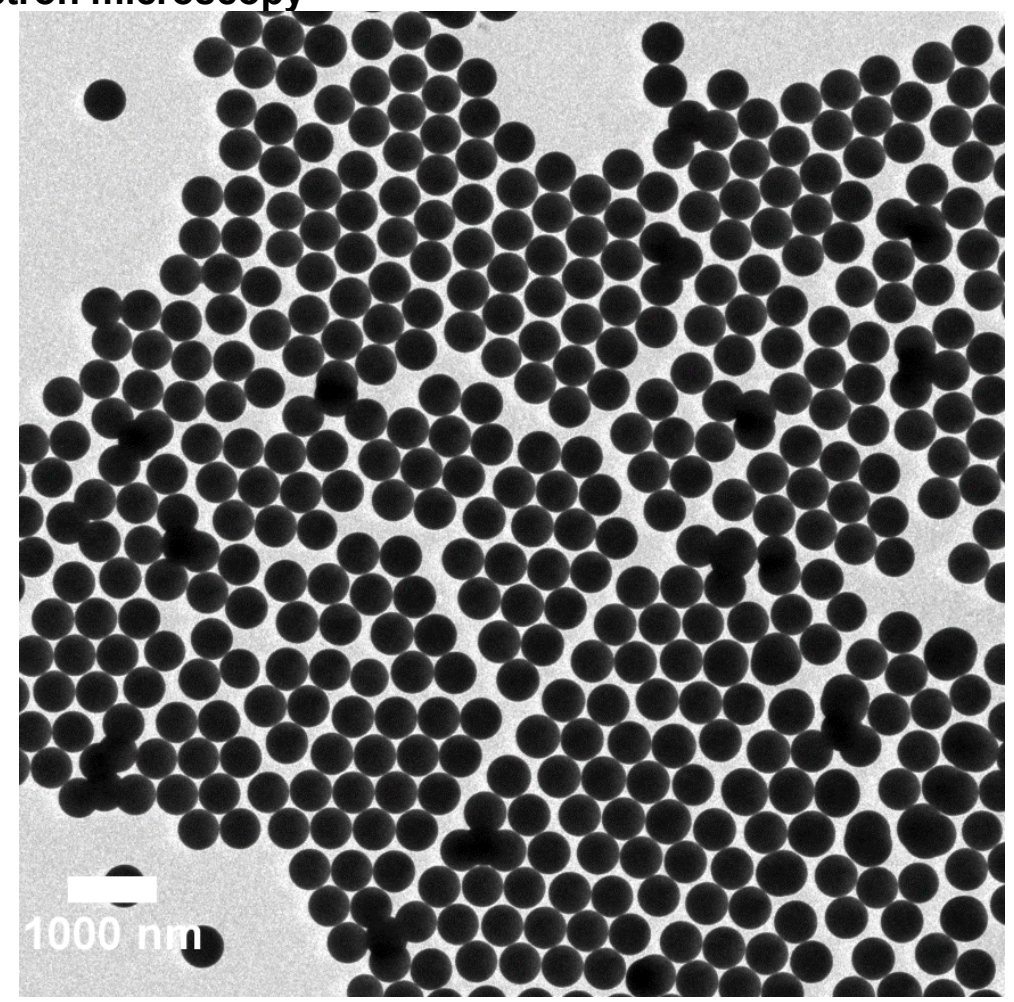

Figure $\mathbf{S 6}$ Transmission electron micrograph of the synthesized nanoparticles NP1. Scale bar represents $1000 \mathrm{~nm}$. 


\section{Dynamic light scattering}

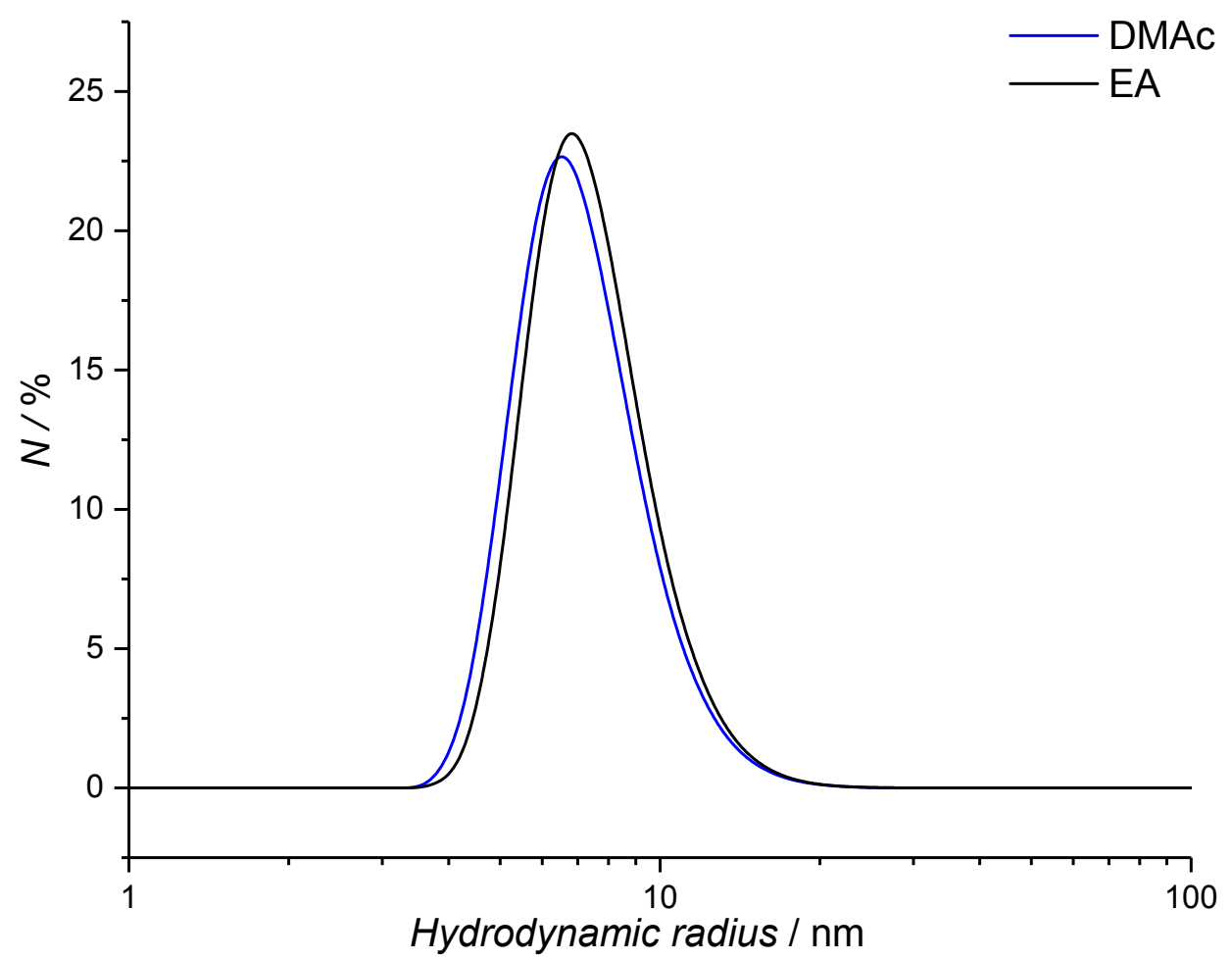

Figure $\mathbf{S} 7$ Hydrodynamic radii of $\mathbf{P 1}$ in DMAc $(7.3 \mathrm{~nm}$, black) and ethyl acetate $(7.6 \mathrm{~nm}$, blue) obtained via DLS.

\section{Calculations}

7.1 Radius of gyration

$$
R_{\mathrm{g}}=b N^{n}=0.153 \mathrm{~nm} \cdot 2157^{0.5} \approx 7.1 \mathrm{~nm}
$$

With $b=0.153 \mathrm{~nm}$ for the smallest freely rotating unit (in this case a C-C bond was used for calculation), $N$ the degree of polymerization and $n=0.5$ the solvent interaction parameter (here used for $\theta$-conditions). ${ }^{[6]}$

\subsection{MMD calculation}

For the calculations of the MMD a symmetrical Gaussian distribution with following shape was used:

$$
\begin{gathered}
M M D=A \cdot \frac{\sqrt{2 / \pi}}{w} \exp \left(-2 \cdot \frac{\left(x-x_{c}\right)^{2}}{w}\right) \\
\rightarrow M M D_{\text {sur }}=\kappa \cdot M M D \cdot f \text { with the condition } \int M M D_{\text {sur }}=\frac{1}{2} \int M M D \rightarrow M M D_{\text {sol }}=M M D-M M D_{\text {sur }}
\end{gathered}
$$

With $A=2,000,000$ [g/mol] $, \mathrm{w}=220,000$ and $\mathrm{xc}=500,000$. The shifted surface distributions $M M D_{\text {sur }}$ where calculated by multiplying the starting $M M D$ with $\kappa$ (from Equation 1 in the main paper), with the condition (as a correction factor) that the resulting graph area must be $50 \%$ of the starting graph area. The solution distribution after grafting, $M M D_{\text {sol }}$, was calculated subtracting the surface distribution $M M D_{\text {sur }}$ from the starting distribution $M M D$. All $M M D$ s where normalized before plotting. To investigate various solvent interaction

\begin{tabular}{|c|c|c|c|c|c|c|}
\hline$n$ & $A$ surf. & w surf. & $x_{\mathrm{C}}$ surf. & A sol. & w sol. & $x_{\mathrm{c}}$ sol. \\
\hline 0.1 & 999,834 & 220,571 & 497,503 & $1,000,221$ & 219,333 & 502,475 \\
\hline 0.2 & 999,640 & 221,159 & 494,978 & $1,000,620$ & 218,467 & 504,923 \\
\hline 0.3 & 999,419 & 221,764 & 492,425 & $1,001,259$ & 217,420 & 507,333 \\
\hline 0.4 & 999,166 & 222,387 & 489,842 & $1,002,218$ & 216,217 & 509,692 \\
\hline 0.5 & 998,872 & 223,029 & 487,227 & $1,003,583$ & 214,882 & 511,989 \\
\hline 0.6 & 998,527 & 223,690 & 484,581 & $1,005,443$ & 213,444 & 514,213 \\
\hline 0.7 & 998,115 & 224,370 & 481,901 & $1,007,894$ & 211,931 & 516,354 \\
\hline 0.9 & 996,984 & 225,785 & 476,435 & $1,014,954$ & 208,797 & 520,354 \\
\hline
\end{tabular}
parameters $n$, the following values were used for the Gaussian distributions.

Table S3 Gaussian distribution parameters used in the calculations. 
7.3 Normalization of $M M D$

For the normalization of all MMD, OriginLab OriginPro's 2017 normalize to $[0,1]$ function was used (which represents a common way of normalization and can be performed by any calculation program). Suppose $Y$ is the $y$ values of input curve, then the normalized curve $Y^{\prime}$ is:

$$
Y^{\prime}=\frac{Y-Y_{\min }}{Y_{\max }-Y_{\min }}
$$

\section{References}

[1] J Schindelin, I. Arganda-Carreras, E. Frise, V. Kaynig, M. Longair, T. Pietzsch, S. Preibisch, C. Rueden, S. Saalfeld, B. Schmid, J.-Y. Tinevez, D. J. White, V. Hartenstein, K. Eliceiri, P. Tomancak, A. Cardona, Fiji: an open-source platform for biological-image analysis, Nature Methods 2012, 9, 676.

[2] C. T. Rueden, J. Schindelin, M. C. Hiner, B. E. DeZonia, A. E. Walter, E. T. Arena, K. W. Eliceiri, ImageJ2: ImageJ for the next generation of scientific image data, BMC Bioinformatics 2017, 18, 529.

[3] K. A. Gunay, N. Schuwer, H.-A. Klok, Synthesis and post-polymerization modification of poly(pentafluorophenyl methacrylate) brushes, Polymer Chemistry 2012, 3, 2186-2192.

[4] G. Moad, Y. K. Chong, A. Postma, E. Rizzardo, S. H. Thang, Advances in RAFT polymerization : the synthesis of polymers with defined end-groups, Polymer 2005, 46, 8458-8468.

[5] C. C. M.-C. Carcouet, Chemistry and morphology of silica nanoparticles, Technische Universiteit Eindhoven (Eindhoven), 2014.

[6] L. Michalek, L. Barner, C. Barner-Kowollik, Polymer on Top: Current Limits and Future Perspectives of Quantitatively Evaluating Surface Grafting, Advanced Materials, 2019, 30, 1706321 